\title{
Teaching Reform and Practice of the Provincial-level Quality Course: Quantum Mechanics
}

\author{
Hongmei Wang \\ Department of Physics, Dezhou University, Dezhou 253023, China \\ Tel: 86-534-8985-398_E-mail:whm_2327@126.com \\ The research is financed by the "Study on the Applied Talents Cultivation Mode of Chinese Colleges" of \\ "Eleventh Five-Year" National Project of Applied Undergraduate Colleges (No. FIB070335-A3-16). \\ (Sponsoring information)
}

\begin{abstract}
According to the actuality of Dezhou University, some useful reforms in teaching content, teaching method, and teaching measure are introduced, combining with the characteristics of the course of quantum mechanism in this article.

Keywords: Quantum mechanics, Teaching reform, Teaching content, Teaching strategy

The quantum mechanics is one of two backbones of the modern physics, and it is the most important required major course in the physics specialty. It is deeply applied not only in many branches of physics, but also quickly and extensively in many important domains such as chemistry, biology, material science, and information science. By the studying of this course, students could masterly grasp the basic concepts and theories of the quantum mechanics, and have the basic theories of quantum mechanics to analyze the solve problems. The course of "quantum mechanics" of the department of physics of Dezhou University was appraised as the Shandong Provincial provincial-level quality course, and by virtue of this chance, the teaching content and method of quantum mechanics are reformed, and primary results have been obtained.
\end{abstract}

\section{Main ideas of the teaching reform}

In the traditional teaching, teacher is authority and students must accept the knowledge taught by the teacher without any condition. In the new term, this traditional concept should be changed, because the traditional concept would gradually cultivate students' dependence on teacher to be habits accordingly. Students dare not doubt their teachers, not to speak of the authority, so students' individuality and creation would be killed. To cultivate the innovational talents and implement new teaching concepts, and advocate the people-oriented concept, both students' principal function and teacher's domain function should be exerted, and the quality education should be carried out. Some reforms in the teaching content, teaching method, and teaching measure in quantum mechanics could really enhance the quality of talent cultivation.

\section{Reform of teaching contents}

Teaching content is the most basic factor in the teaching activity, and it would directly influence the teaching effect. When explaining the basic concepts and the basic computation method, the mathematical knowledge would be used inevitably, and students are not required to grasp complex mathematical deduction process, so the physical contents should not be submerged in the complex mathematical form. Proper teaching method could make students not only to grasp the application of mathematics in the course, but avoid complex mathematics, and centralize their energies to understand the physical concepts of the quantum mechanics, and grasp the basic concepts of the quantum mechanics. For example, for the one-dimensional harmonic oscillator and hydrogen atom, only the idea, method, and conclusions should be mainly introduced, and the detailed deduction is not necessary.

Students should be instructed to study the classic literatures, which could not only enhance students' level of foreign language, and cultivate their ability to primarily read professional literatures, but also let students to listen on the masters' voice, study the masters' thinking and expression mode, and enhance their studying interests.

In the instruction of basic theories, the "interface" between the teaching content and the frontier development of physics should be set up to make students to know the development trend of physics and expand their views. At the same time, the special lectures about the frontier knowledge of physics should be added (Zhao, 2001, P.78 \& Lei, 2005, P.39 \& Fan, 2005, P.47). Some special lectures about the quantum mechanism such as the quantum information theory, the application of quantum mechanics in the nanotechnology, and the application of quantum mechanics in the biological technology should be developed to expand student's knowledge. 
Some exploring works could be given to students, for example, deeply developing certain problem of quantum mechanics, or surveying the relative frontier problem of quantum mechanics, to primarily cultivate part students' research ability.

\section{Reforms of teaching measure and method}

Traditional cultivation mode and teaching concept make against students' development in their innovational thinking and ability (Li, 2001, P.14). Effective teaching method and measure are the guarantee to realize the target of the education, and in the teaching activity, the educational psychology rule should be followed, and the teaching should start not only from the requirements of the teaching subject and teaching content, but from the psychological development rule of college students, and colleges should establish effective teaching strategy, reform the teaching method, adopt multiple teaching measures, and flexibly apply above measures in the teaching, and make the teaching achieve the requirements of knowledge and ability, quality and method, and present the teaching form according with students' learning characteristics.

\subsection{Changing traditional teaching method and cultivating students'scientific quality}

Traditional teaching method is the "force-feed duck" instruction, and this method makes students in the passive state in the teaching, and goes against the acquirement of knowledge and the cultivation of innovational ability. Aiming at this situation, the teaching method is improved, and the "research-type teaching" is adopted (Lu, 2004) in Dezhou University, which could fully utilize the teaching resource and advantages, and enhance the teaching quality, and cultivate students' science quality and research ability, and establish the base for their higher learning and work. The concrete method can be described as follows. Teachers first require students to prepare the course, and create the question situation in the teaching to lead students to discuss and research. Teachers should certainly explain the physical essential and ideas clearly, so students could not only acquire physical knowledge and learn something in the scientific thinking and methodology. By creating the question situations such as the multiple solutions of one question, or selecting some hotspots and difficult points in the teaching, teachers and students could communicate each other, which could largely enhance students' learning interests, and for the problems which could not be solved in the classroom, teachers should encourage students to solve it after school by other resources such as internet.

The form of the course paper could train students' ability of scientific research, and some incomplete solutions of the problems, and the interfaces of quantum mechanics with other subjects all can be the topics for students' paper, and some students could take them as their own projects. Up to now, students have studied the quantum entanglement and decoherence, the potential function and spectrum constant, the experiments about the quantum mechanics, and the quantum mechanics and biological physics. This method could not only establish the base for the training of scientific research, but more deeply understand and grasp the knowledge. At the same time, students also could study the scientific criterions to offer firm knowledge base, innovational consciousness, and skill training for future research. In the concrete implementation, students' papers are not required to appear, but the topic, content, format, literature reference of the papers should use the writing criterions of academic thesis.

\subsection{Enriching the classroom teaching measures}

The classroom teaching measure should gradually be changed from the single electric courseware to the combination of electric teaching plan, writing on blackboard, video, CAI courseware, demonstrated experiment, and network, for achieving the best teaching effect.

(1) As an effective assistant measure of modern teaching, the multimedia technology is more and more welcomed by most teaching staffs. The appearance of the multimedia teaching brings the vital force in the classroom education, and its powerful demonstration function is unmatched for traditional teaching measures. By using multiple modes such as projection, animation, and sound to transfer information, teachers could optimize the teaching process, and change the formalistic teaching classroom to be lively teaching place. Students' enthusiasm and innovation would be inspired largely, and the dual-communication between "teaching" and "learning" is fully embodied, so the efficiency of the classroom teaching will be largely enhanced.

(2) Physics is an experiment science, and to observe the experiment phenomena is an important measure to obtain physical knowledge. The university also established the lab of quantum mechanics, and set up 12 experiments including the electron spin resonance, the laser Raman spectroscopy, and the optical pumped magnetic resonance. After several years' teaching practice, students' study interests have been largely enhanced.

(3) The university developed the digital software in the teaching. The quantum effect, quantum model, quantum principle, quantum computation, quantum experiment, and quantum application in the quantum mechanics are very abstract and difficult, and the teaching effect is not significant for a long term, but the development of 
software by the digital technology could fully utilize the computation and simulation technology, and display visually the difficult knowledge before students, and change the abstract knowledge into the intuitionistic knowledge, and the good teaching effect has proved this method.

(4) The university has established cubic quantum mechanics course digital teaching source base for students' learning after school. The characteristic of college students' learning is to combine the classroom learning with the learning after school. But many learning resource after school in many colleges only includes the teaching plan and exercises answer of teachers, which could not effectively help students' learning. Since the digitization of education information occurred in the middle term of 1990s, it continually pushed the reform and innovation of traditional electric education and CAE. At present, large numbers of good digital resources about the course of quantum mechanics in the domestic and foreign network teaching resource are very abundant, the colleges could establish the cubic quantum mechanic digital resource base, assistant teaching software, management software, information consultation and network teaching resource base by fully collecting good teaching resources, combining teachers' teaching practice and teaching researches, selecting, integrating, and creating existing digital teaching resources by virtue of modern information technology and new teaching concepts. Especially, the colleges should establish the multiple-information courseware base according to the modern courseware idea, and utilize the combination of courseware to teaching on the internet. The colleges should provide a self-educated cubic space for the learning after school.

Above contents are the primary practice and experience in the construction of the course. The reform and innovation of teaching is the powerful drive to implement the college education, and in the teaching process, the colleges should combine with students' actual situation and the situation of the modern education, and continually reform the teaching content, teaching method, and teaching measures. Only in this way, high-quality talents required by the country could be cultivated really.

\section{References}

Fan, Hongyi. (2005). From Quantum Mechanics to Quantum Optics: Physical Development. Shanghai: Shanghai Jiaotong University Press. P.47.

Lei, Yi'an (Antony Head \& Patrili Walters). (2005). New Quantum World. Changsha: Hunan Science and Technology Press. P.39.

Li, Yuanjie \& Sun, Weina. (2001). Giving Students Tools and Methods in Studying: A Studying Model for Students Study Voluntarily under Teacher's Instructions. Physics and Engineering. No.11(5). P.14.

Lu, Dexin. (2004). Research Teaching of College Physics. Physics and Engineering. No.52(1).

Zhao, Kaihua \& Luo, Weiyin. (2001). Quantum Physics. Beijing: Higher Education Press. P.78. 